Received 00th January 20xx, Accepted 00th January $20 x x$ DOI: $10.1039 / x 0 x \times 00000 x$

\section{Linear assembly of lead bromide-based nanoparticles inside lead(II) polymers prepared by mixing the precursors of both the nanoparticle and the polymer}

\author{
Soranyel Gonzalez-Carrero, ${ }^{a}$ Lorena Bareño, ${ }^{a}$ Elke Debroye,${ }^{b}$ Cristina Martin, ${ }^{\mathrm{b}}$ Patricia Bondia, ${ }^{\mathrm{c}}$
} Cristina Flors, ${ }^{\mathrm{c}}$ Raquel E. Galian, ${ }^{\mathrm{a}}$ Johan Hofkens ${ }^{\mathrm{b},{ }^{*}}$ and Julia Pérez-Prieto ${ }^{\mathrm{a},{ }^{*}}$

www.rsc.org/

\begin{abstract}
Mixing precursors of lead(II) polymers with those of lead bromidebased nanoparticles $\left(\mathrm{CH}_{3} \mathrm{NH}_{3} \mathrm{PbBr}_{3}\right.$ perovskites or $\left.\mathrm{PbBr}_{2}\right)$, at room temperature and in the presence of cyclohexanemethylammonium bromide, generated colloidal nanocomposites which, when deposited on a hydrophobic surface led to long, form onedimensional, ordered and well-defined architectures.
\end{abstract}

Lead halide perovskites present an $\mathrm{APbX}_{3}$ formula, where $\mathrm{A}$ is a small organic cation, such as methylammonium (MA), formamidinium (FA) or cesium cation, $\mathrm{X}$ is a halide anion ( $\mathrm{Cl}-\mathrm{Br}^{-}$ and/or $\mathrm{I}^{-}$) or a mixture of halides. Colloidal lead halide perovskites exhibit broad and intense absorption in the UV-VIS range, high photoluminescence and narrow emission, and solution-processability. ${ }^{1-3}$ Their outstanding optical and electronic properties are motivating the use of $\mathrm{APbX}_{3}$ nanoparticles not only in light emitting devices, solar cells and photodetectors, but also in sensing and photocatalysis. ${ }^{4-7}$ There is an increasing interest in the assembly of nanoparticles into superstructures with well-defined geometry to create new materials with potential novel applications. ${ }^{8-10}$ The assemblage of nanoparticles into one-dimensional (1D) ordered and welldefined architectures, two-dimensional (2D) membranes and close-packed three dimensional (3D) superlattices is usually driven by interactions between nanoparticles, such as Van der Waals forces, electrostatic and dipole-dipole interactions. ${ }^{11}$ Colloidal nanoparticles can also be organized into ordered architectures by making use of template methods. In this way, colloidal nanoparticles, such as, $\mathrm{CdTe}, \mathrm{ZnO}$, silver, gold and lead halide perovskite nanoparticles have been assembled by using

\footnotetext{
a. Instituto de Ciencia Molecular (ICMoL), Universidad de Valencia, Catedrático José Beltrán 2, 46980, Paterna, Valencia, Spain.

b. Department of Chemistry, KU Leuven, Celestijnenlaan 200F, B-3001, Leuven, Belgium

Madrid Institute for Advanced Studies in Nanoscience (IMDEA Nanociencia), Faraday 9, 28049, Madrid, Spain

Electronic Supplementary Information (ESI) available: Experimental methods, characterization techniques, correlative fluorescence and AFM, and FLIM studies. See DOI: $10.1039 / x 0 x x 00000 x$
}

biomolecules (DNA, proteins) and inorganic templates (nanowires and nanotubes) and external fields. ${ }^{12-16}$

Focusing on lead halide perovskites, and particularly on the formation of 1D, ordered superstructures, it has recently been reported that the co-assembly of pre-formed $\mathrm{CsPbX}_{3}$ nanoparticles and lamellar ribbons, formed from the association of $\mathrm{PbSO}_{4}$-oleate clusters in hexane, eventually provides long and continuous 1D low-dimensional architectures. ${ }^{17,} 18$ To our knowledge, similar assemblies based on organic-inorganic hybrid lead halide perovskite nanoparticles have not been reported so far.

Unlike all-inorganic lead halide perovskite nanoparticles, hybrid lead halide perovskites can be efficiently prepared at room temperature by injecting a solution of the perovskite precursors (e.g., $\mathrm{PbBr}_{2}, \mathrm{MABr}$ and a medium-sized ammonium bromide salt) into a toluene. In addition, this year Rezvani et al. ${ }^{19}$ succeeded in preparing a 1D lead(II) coordination polymer with the formula $\left[\mathrm{Pb}_{2} \mathrm{~L}_{2} \mathrm{I}_{4}\right]_{\mathrm{n}}$ (L: 1-methylimidazole), in which each $\mathrm{L}$ is coordinated to one $\mathrm{Pb}$, using $\mathrm{Pb}\left(\mathrm{NO}_{3}\right)_{2}, \mathrm{KI}$, and 1methylimidazole as the polymer precursors.

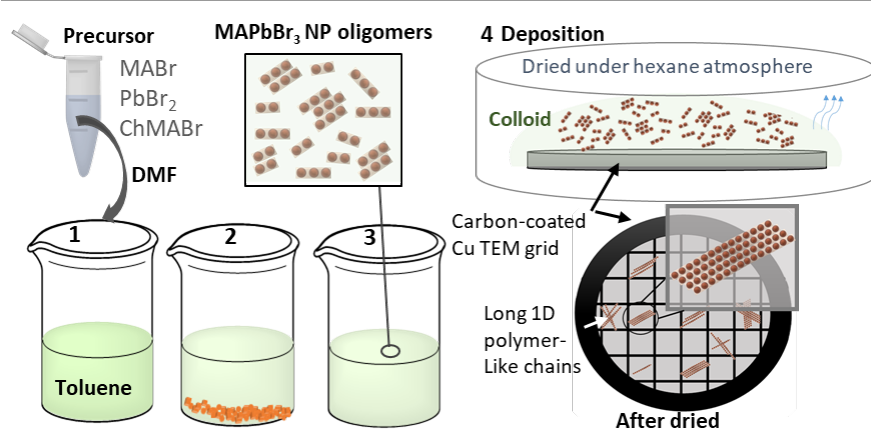

Figure 1. Schematic representation of the new strategy for preparing ordered assemblies of $\mathrm{MAPbBr}_{3}$ perovskites inside lead(II) coordination polymers: synthesis of colloidal $\mathrm{MAPbBr}_{3} \mathrm{NP}$ oligomers (1-3) and their transformation into 1D $\mathrm{MAPbBr}_{3}$ nanoparticle polymers after their deposition on a carbon-coated CU TEM grid and drying under hexane atmosphere. 
Taking into account the mild conditions for the preparation of the hybrid perovskites and the possibility of forming 1D lead halide coordination polymers, we explored if injecting the mixture of all the precursors (both of the perovskite and the coordination polymer) into a low-polar solvent could provide ordered assemblies of lead halide-based nanoparticles, namely $\mathrm{MAPbBr}_{3}$ perovskites, inside lead(II) coordination polymers. ${ }^{20,21-}$ ${ }^{23}$ Here we describe, for the first time, the preparation of 1D assemblies of lead halide-based nanoparticles $\left(\mathrm{PbBr}_{2}\right.$ or $\mathrm{MAPbBr}_{3}$ ) inside a lead bromide polymer, by concurrent formation of lead(II) oligomers and the nanoparticles in the presence of cyclohexanemethylammonium bromide ( $\mathrm{ChMBr}$ ) to lead to colloidal nanoparticle oligomers (Figure 1).

Deposition of the colloid on a carbon-coated copper TEM grid led to long, 1D, ordered and well-defined architectures; both the $\mathrm{PbBr}_{2}$ and the $\mathrm{MAPbBr}_{3}$ assemblies showed a high degree of linearity of several microns in length when they were dried under a hexane saturated atmosphere. By contrast, deposition of the $\mathrm{MAPbBr}_{3}$ and $\mathrm{PbBr}_{2}$ colloids on glass slides provided spherical aggregates, those arising from the former being smaller and more homogeneous (see below). The $\mathrm{MAPbBr}_{3}$ assembly and its luminescence performance was studied in depth by using transmission electronic microscopy (TEM), scanning electron microscopy (SEM), correlative atomic force microscopy (AFM) and single particle fluorescence imaging, and fluorescence lifetime microscopy (FLIM).

With the focus on the preparation of assemblies consisting of lead halide perovskites inside a lead(II) polymer, we tested the combination of $\mathrm{PbBr}_{2}$ in dimethylformamide (DMF) with different $\mathrm{MABr}$ :ChMABr molar ratios (Figure S1). ${ }^{24}$ We describe here the most successful preparation. Briefly, a DMF solution containing $\mathrm{PbBr}_{2}, \mathrm{MABr}$, and $\mathrm{ChMABr}$ in a 1:0.93:0.07 molar ratio was added dropwise to toluene $(5 \mathrm{~mL})$ and stirred for 60 minutes at room temperature. The yellow colloidal solution was left to stand for 24 hours and then it was decanted. The precipitate (ca. $50 \%$ of the added material) consisted of bulk perovskite and was discarded.

The absorption spectrum of the supernatant showed the formation of a $\mathrm{MAPbBr}_{3}$ colloid with an exciton peak at $523 \mathrm{~nm}$ (Figure 2a). The colloid exhibited photoluminescence $(P L)$ with maximum at $530 \mathrm{~nm}$ (full width at half maximum, FWHM $=24$ $\mathrm{nm}$ ) and a PL quantum yield $\left(\Phi_{\mathrm{PL}}\right)$ of $35 \%$ (Figure $2 \mathrm{~b}$ ). Timeresolved PL measurements showed a considerably long average lifetime ( $\left.\tau_{\mathrm{av}} 769 \mathrm{~ns}\right)$ and the decay kinetics fitted to a threeexponential decay function (inset in Figure 2c, table S1). ${ }^{25}$

The TEM and SEM images of the $\mathrm{MAPbBr}_{3}$, deposited by drop casting of the colloid onto a carbon-coated copper grid surface and then dried under hexane atmosphere, showed the formation of bunches of 1D polymer-like chains of several microns in length, containing $7 \mathrm{~nm}$-sized nanoparticles $(7.2 \pm 0.8$ $\mathrm{nm}$ ) with an average inter-particle distance of $7.0 \pm 3.0 \mathrm{~nm}$ calculated from TEM images. Then, control assays were carried out in the absence of $\mathrm{MABr}$ under the same conditions. Remarkably, the deposition of the non-emissive colloid led to the formation of similar 1D polymer-like chains of several microns in length but containing $\mathrm{PbBr}_{2}$ nanoparticles (Figure S2).
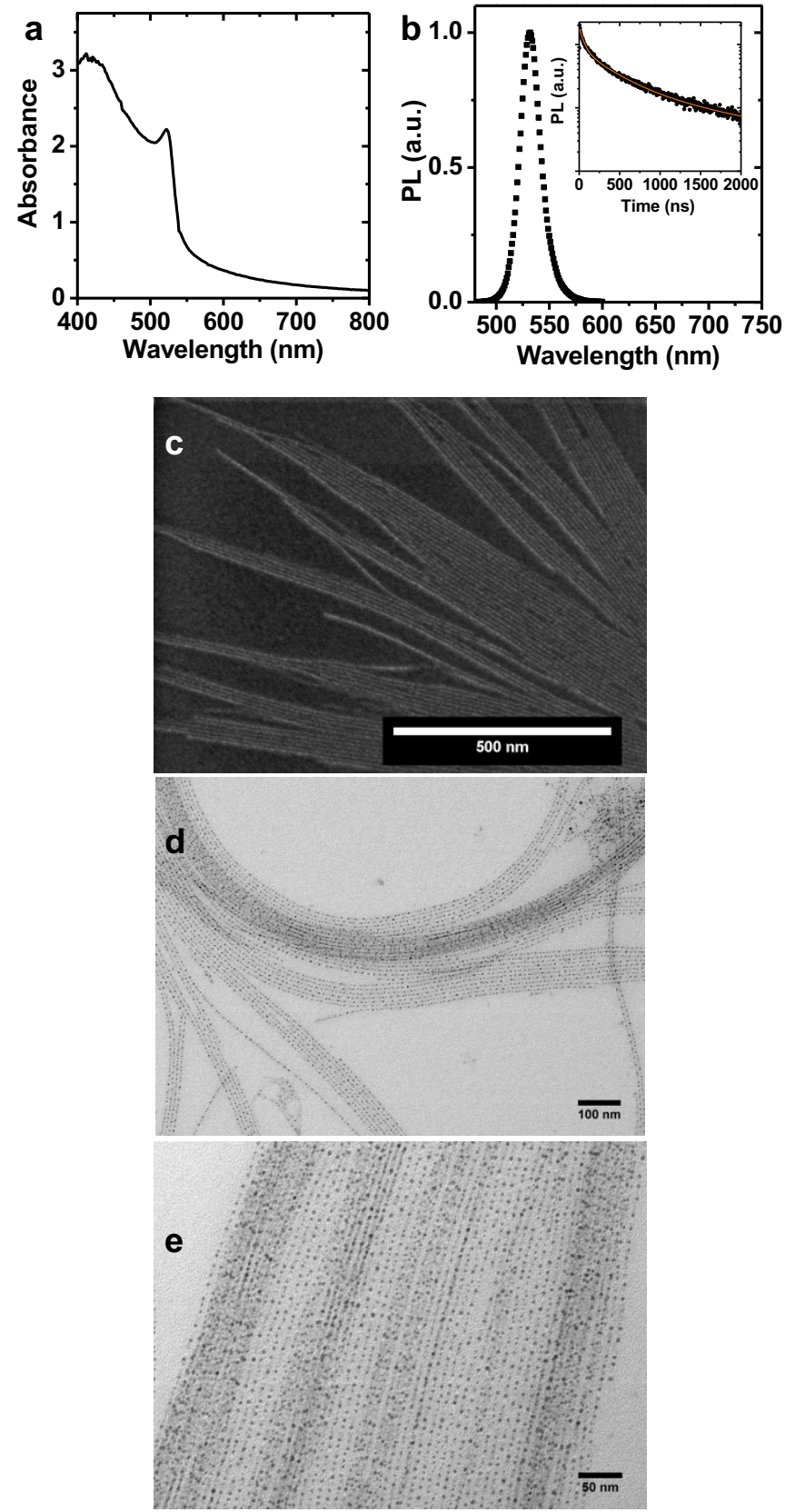

Figure 2. a) Absorption and b) normalized PL emission spectra of the $\mathrm{MAPbBr}_{3}$ colloid. Inset image b: PL lifetime decay trace of the colloid. c) SEM and d,e) TEM images of the $\mathrm{MAPbBr}_{3}$ colloid deposited on a carbon-coated TEM grid and dried under saturated atmosphere of hexane.

The powder X-ray diffraction (PXRD) and energy dispersive diffraction (EDS) spectra of the 1D $\mathrm{MAPbBr}_{3} \mathrm{NP}$ polymer were consistent with the formation of the perovskite cubic phase $(P m-3 m)$ with an average $\mathrm{Br}: \mathrm{Pb}$ ratio of 2.9 , Figure $\mathrm{S3}^{2}{ }^{2} 26,27$ Additional studies for composition analysis were performed by using thermogravimetric analysis (TGA) and proton nuclear magnetic resonance $\left({ }^{1} \mathrm{H}-\mathrm{NMR}\right)$, see experimental details in ESI. The TGA heating curve showed two weight losses at $329^{\circ} \mathrm{C}(19$ $\%)$ and $566^{\circ} \mathrm{C}(81 \%)$, attributed to the organic ammonium salts ( $\mathrm{MABr}$ plus $\mathrm{ChMABr}$ ) and $\mathrm{PbBr}_{2}$, respectively (Figure $\mathrm{S} 3$ ). ${ }^{28}$ The ${ }^{1} \mathrm{H}-\mathrm{NMR}$ spectra revealed that the organic ligand $\mathrm{ChMABr}$ was present in the colloidal nanoparticles and not in the discarded 
solid (Figure S4). Moreover, the X-ray photoelectron spectroscopy analysis the $\mathrm{MAPbBr}_{3} \mathrm{NP}$ polymer and that of the sample prepared in the absence of $\mathrm{MABr}$, i.e., the $1 \mathrm{D} \mathrm{PbBr}_{2} \mathrm{NP}$ polymer, Figure S5 and S6, confirm the presence of lead(II) in both polymers (see details of the analysis in ESI).

Attempts were made to obtain 1D ordered superstructures of $\mathrm{MAPbBr}_{3}$ nanoparticles by drop-casting the colloid onto a hydrophobic glass slide followed by drying under a saturated hexane atmosphere with a view to obtaining information about their emissive properties (see experimental details in ESI). The AFM and SEM images (Figures $3 \mathrm{a}-\mathrm{c}$ ) revealed a homogeneous distribution of a larger $\mathrm{MAPbBr}_{3}$ nanomaterial (about $30 \mathrm{~nm}$ ) that could have originated from the clumping of nanoparticle oligomers, from now onward termed as clumped $\mathrm{MAPbBr}_{3} \mathrm{NP}$ oligomers, $\mathrm{MAPbBr}_{3}$ cNP oligomer. This behaviour could be attributed to phobic interactions between the glass substrates and the colloid, Figures $3 \mathrm{a}, 3 \mathrm{~b}$ and $3 \mathrm{c}$. The inter-particle distance between the $\mathrm{CNP}_{\text {oligomer }}$ on the hydrophobic glass was estimated as $51 \pm 23 \mathrm{~nm}$ from the SEM images (Figure S2 shows the analogous $\mathrm{PbBr}_{2} \mathrm{CNP}_{\text {oligomer }}$ from the control sample).

Even though the deposition of the $\mathrm{MAPbBr}_{3}$ colloid on the hydrophobic glass could not be used to support the 1D nanoparticle polymer observed on the TEM grid, we turned our attention to investigating the $\mathrm{PL}$ features of the $\mathrm{MAPbBr}_{3}$ CNP oligomer sample. It showed an absorption and emission peak at $519 \mathrm{~nm}$ and $530 \mathrm{~nm}$, respectively, Figure $3 \mathrm{~d}$ (see details in the experimental section in ESI). It was possible to record PL of single $\mathrm{CNP}_{\text {oligomer }}$ by using correlative AFM and fluorescence microscopy, with laser excitation at $488 \mathrm{~nm} .29,30$ The correlation showed that $90 \%$ of the individual $\mathrm{MAPbBr}_{3} \mathrm{CNP}_{\text {oligomer }}$ observed by AFM were emissive and characterised by strong $\mathrm{PL}$ intermittency or blinking (Figure S7). Considerable differences in intensity, frequency and duration of blinking were observed (Figure S7); a similar behaviour has previously been observed for $\mathrm{MAPbl}_{3}$ and $\mathrm{MAPbBr}_{3}$ crystals and films. ${ }^{31,32}$ No clear dependence of the emission behaviour on the morphology and height of the $\mathrm{MAPbBr}_{3} \mathrm{cNP}_{\text {oligomer }}$ was observed. The PL intermittency in hybrid lead halide perovskite nanoparticles has been attributed to trap states, associated with chemical or crystal defects. ${ }^{31-37}$ The $\mathrm{PL}$ decays of $\mathrm{MAPbBr}_{3} \mathrm{cNP}_{\text {oligomer }}$ collected from the FLIM images exhibited exponential decay kinetics that fit to a biexponential function (laser excitation at $488 \mathrm{~nm}$, Figure 3e). The PL $\tau_{\text {av }}$ was $74 \mathrm{~ns}$, with $\tau_{1}=14 \mathrm{~ns}, \tau_{2}=90$ ns (Figure S8, Table S2). Figure $3 f$ shows the frequency histograms of the average PL lifetime obtained from the pixels analysed in different regions of the FLIM image. These regions exhibited a broad lifetime distribution centred at $100 \mathrm{~ns}$. Similar results ( $\tau_{\mathrm{av}}$ of $100 \mathrm{~ns} ; \tau_{1}=16 \mathrm{~ns}, \tau_{2}=120 \mathrm{~ns}$ ) were obtained by conventional time-resolved $\mathrm{PL}$ spectroscopy measurements (light emitting diode excitation at $470 \mathrm{~nm}$ ). The shortening of the PL $\tau_{\mathrm{av}}$ and the fitting of the exponential decay kinetics to a biexponential function, instead of to a triexponential function as compared to the colloid, can be attributed to disassembling of the aggregates of NP oligomers (see Figure 1) when depositing them on the glass substrate. ${ }^{38,39}$
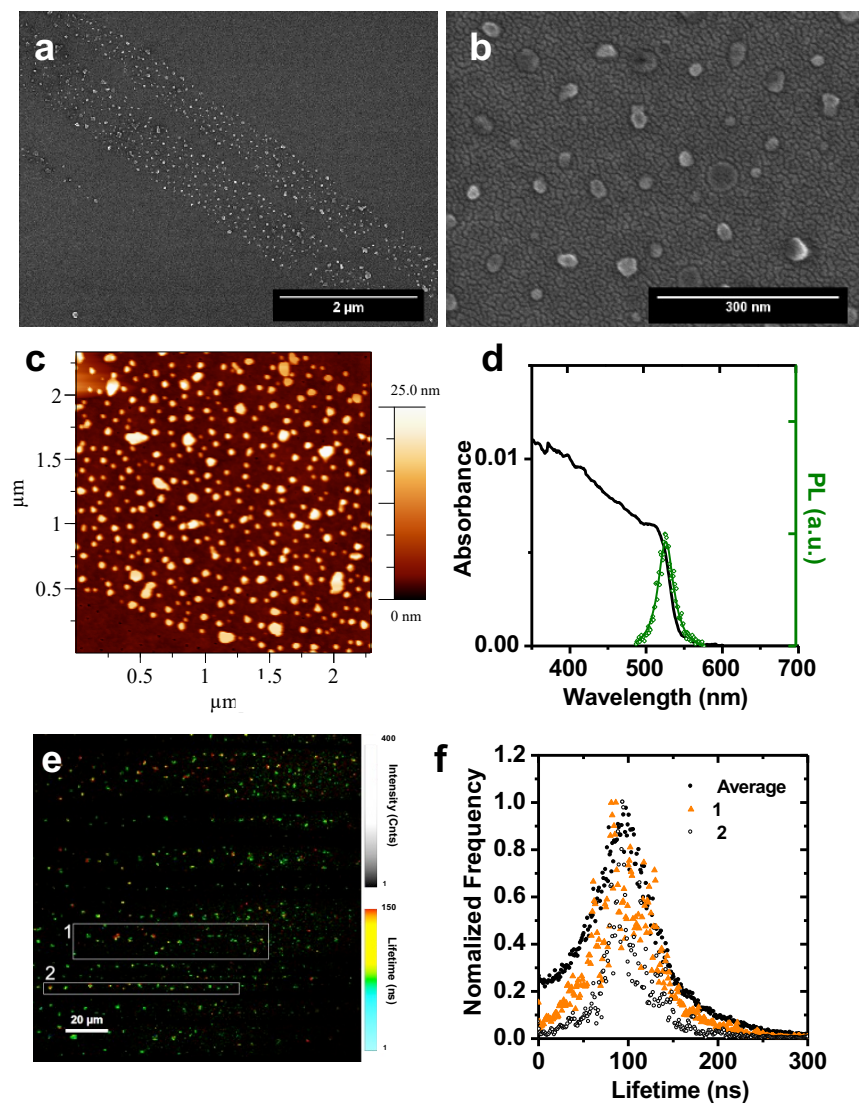

Figure 3. (a,b) SEM images, (c) topographic AFM image, (d) absorption and emission spectra $\left(\lambda_{\text {exc }}=470 \mathrm{~nm}\right)$ and (e) FLIM image of the $\mathrm{MAPbBr}_{3}$ colloid deposited on hydrophobic glass. (f) PL lifetime histograms collected from the selected area in image e. Scale bars: $2 \mu \mathrm{m}(\mathrm{a}), 300 \mathrm{~nm}$ (b), and $20 \mu \mathrm{m}$ (e).

A double-layer light-emitting device based on the colloidal $\mathrm{MAPbBr}_{3}$ nanoparticle oligomers in toluene $(\sim 40 \mathrm{~nm})$ showed similar features to those previously reported for a device built from a $\mathrm{MAPbBr}_{3}$ nanoparticle colloid, ${ }^{40}$ with a turn-on voltage of $2 \mathrm{~V}$ and a narrow electroluminescence band centred at 534 $\mathrm{nm}(\mathrm{FMWH}=29 \mathrm{~nm})$, Figure S9.

In summary, we report here the linear assembly of photoluminescent methyl ammonium lead bromide nanoparticles inside a lead(II) polymer by means of a simple and one-step method starting from the precursors of both materials and cyclohexylammonium bromide. This also applies to lead bromide; the assemblies are built under the same conditions but in the absence of methylammonium bromide. Deposition of the colloid on the hydrophobic surface of carbon-coated copper TEM grid led to long, 1D, ordered and well-defined architectures, while deposition of the colloid on glass slides provided spherical aggregates. The correlative single-particle fluorescence and AFM showed that ordered and non-connected $\mathrm{MAPbBr}_{3} \mathrm{NP}$ oligomers were mostly emissive and showed PL intermittency. The lifetime distribution of the ordered NP oligomers was narrow.

In future work we foresee the use of first-principles density functional theory calculations to understand all mechanistic aspects of the obtained assembly and, consequently, for designing new nanoparticles superlattices. ${ }^{41,42}$ 
Finally, this strategy could enable the linear assembly of perovskites with other functional nanoparticles to produce relevant hybrid systems.

This work was supported by the MINECO (CTQ2014-60174, CTQ2017-82711-P partially co-financed with FEDER funds and pre-doctoral grant to S.G-C); Maria de Maeztu:MDM-20150538). C.F acknowledges MINECO (MAT2015-66605-P) and Severo Ochoa (SEV-2016-0686). E.D. and C. M. acknowledge financial support from the Research Foundation-Flanders in the form of a postdoctoral fellowship. J.H. acknowledges financial support of from the Research Foundation-Flanders (FWO, Grant No's ZW15_09GOH6316, 12Y6418N and G.098319N), the Flemish government through long-term structural funding Methusalem (CASAS2, Meth/15/04) and the Hercules foundation (HER/11/14).

\section{Conflicts of interest}

There are no conflicts to declare.

\section{Notes and references}

1. F. Zhang, H. Zhong, C. Chen, X.-g. Wu, X. Hu, H. Huang, J. Han, B. Zou and Y. Dong, ACS Nano, 2015, 9, 4533-4542.

2. S. Gonzalez-Carrero, L. Francés-Soriano, M. González-Béjar, S. Agouram, R. E. Galian and J. Pérez-Prieto, Small, 2016, 12, 5245-5250.

3. S. González-Carrero, L. Martínez-Sarti, M. Sessolo, R. E. Galian and J. Pérez-Prieto, Journal of Materials Chemistry C, 2018, 6, 6771-6777.

4. H. Huang, M. I. Bodnarchuk, S. V. Kershaw, M. V. Kovalenko and A. L. Rogach, ACS Energy Letters, 2017, 2, 2071-2083.

5. F. Yan, J. Xing, G. Xing, L. Quan, S. T. Tan, J. Zhao, R. Su, L. Zhang, S. Chen, Y. Zhao, A. Huan, E. H. Sargent, Q. Xiong and H. V. Demir, Nano Lett, 2018, 18, 3157-3164.

6. C. Muthu, S. R. Nagamma and V. C. Nair, RSC Advances, 2014, 4, 55908-55911.

7. H. Huang, H. Yuan, K. P. F. Janssen, G. Solís-Fernández, Y. Wang, C. Y. X. Tan, D. Jonckheere, E. Debroye, J. Long, J. Hendrix, J. Hofkens, J. A. Steele and M. B. J. Roeffaers, ACS Energy Letters, 2018, 3, 755-759.

8. V. T. Cong, E.-O. Ganbold, J. K. Saha, J. Jang, J. Min, J. Choo, S. Kim, N. W. Song, S. J. Son, S. B. Lee and S.-W. Joo, Journal of the American Chemical Society, 2014, 136, 3833-3841.

9. B. Gao, M. J. Rozin and A. R. Tao, Nanoscale, 2013, 5, 56775691.

10. M. A. Boles, M. Engel and D. V. Talapin, Chemical Reviews, 2016, 116, 11220-11289.

11. K. J. M. Bishop, C. E. Wilmer, S. Soh and B. A. Grzybowski, Small, 2009, 5, 1600-1630.

12. M. G. Warner and J. E. Hutchison, Nature Materials, 2003, 2, 272.

13. Z. Tang, B. Ozturk, Y. Wang and N. A. Kotov, The Journal of Physical Chemistry B, 2004, 108, 6927-6931.

14. J. Shiers Matthew, R. Leech, J. Carmalt Claire, P. Parkin Ivan and J. Kenyon Anthony, Advanced Materials, 2012, 24, 52275235.

15. N. Sharma, A. Top, K. L. Kiick and D. J. Pochan, Angewandte Chemie International Edition, 2009, 48, 7078-7082.

16. M. Yue, Y. Li, Y. Hou, W. Cao, J. Zhu, J. Han, Z. Lu and M. Yang, ACS Nano, 2015, 9, 5807-5817.

17. X. Zhang, L. Lv, L. Ji, G. Guo, L. Liu, D. Han, B. Wang, Y. Tu, J. Hu, D. Yang and A. Dong, J Am Chem Soc, 2016, 138, 3290-3293. 18. A. Pan, M. Jurow, Y. Zhao, F. Qiu, Y. Liu, J. Yang, J. J. Urban, L. He and Y. Liu, Nanoscale, 2017, 9, 17688-17693.
19. P. Hayati, S. Suárez-García, A. Gutiérrez, D. R. Molina, A. Morsali and A. R. Rezvani, Ultrasonics Sonochemistry, 2018, 42 , 320-326.

20. We chose cyclohexanemethylammonium bromide for the formation of the colloidal oligomers bearing in mind that the cyclohexyl moiety has been used to stabilize structures due to the considerably favourable Van der Waals interaction between the cyclohexyl groups, see Ref. 21-23.

21. Y. Yoneda, K. Mereiter, C. Jaeger, L. Brecker, P. Kosma, T. Rosenau and A. French, Journal of the American Chemical Society, 2008, 130, 16678-16690.

22. T. Saha, S. Dasari, D. Tewari, A. Prathap, K. M. Sureshan, A. K. Bera, A. Mukherjee and P. Talukdar, Journal of the American Chemical Society, 2014, 136, 14128-14135.

23. A. Roy, A. Gautam, J. A. Malla, S. Sarkar, A. Mukherjee and P. Talukdar, Chemical Communications, 2018, 54, 2024-2027.

24. Increasing the $\mathrm{ChMABr}: \mathrm{MABr}$ ratio led to the competitive formation of perovskites with other stoichiometries, see figure $\mathrm{S} 1$ in ESI.

25. The average PL lifetime of the 10 -fold diluted colloid decreased to $339 \mathrm{~ns}$, table S1.

26. O. Knop, R. E. Wasylishen, M. A. White, T. S. Cameron and M. J. M. V. Oort, Canadian Journal of Chemistry, 1990, 68, 412-422. 27. A. Poglitsch and D. Weber, The Journal of Chemical Physics, 1987, 87, 6373-6378.

28. S. Gonzalez-Carrero, R. E. Galian and J. Perez-Prieto, Journal of Materials Chemistry A, 2015, 3, 9187-9193.

29. P. Bondia, R. Jurado, S. Casado, J. M. Domínguez-Vera, N. Gálvez and C. Flors, Small, 2017, 13, 1603784.

30. R. Jurado, F. Castello, P. Bondia, S. Casado, C. Flors, R. Cuesta, J. M. Domínguez-Vera, A. Orte and N. Gálvez, Nanoscale, 2016, 8, 9648-9656.

31. T. Tachikawa, I. Karimata and Y. Kobori, J Phys Chem Lett, 2015, 6, 3195-3201.

32. X. Wen, A. Ho-Baillie, S. Huang, R. Sheng, S. Chen, H.-c. Ko and M. A. Green, Nano Lett, 2015, 15, 4644-4649.

33. Y. Tian, A. Merdasa, M. Peter, M. Abdellah, K. Zheng, C. S. Ponseca, T. Pullerits, A. Yartsev, V. Sundström and I. G.

Scheblykin, Nano Letters, 2015, 15, 1603-1608.

34. H. Yuan, E. Debroye, G. Caliandro, K. P. F. Janssen, J. van Loon, C. E. A. Kirschhock, J. A. Martens, J. Hofkens and M. B. J. Roeffaers, ACS Omega, 2016, 1, 148-159.

35. H. Yuan, E. Debroye, K. Janssen, H. Naiki, C. Steuwe, G. Lu, M. Moris, E. Orgiu, H. Uji-i, F. De Schryver, P. Samorì, J. Hofkens and M. Roeffaers, The Journal of Physical Chemistry Letters, 2016, 7, 561-566.

36. A. Merdasa, Y. Tian, R. Camacho, A. Dobrovolsky, E. Debroye, E. L. Unger, J. Hofkens, V. Sundström and I. G. Scheblykin, ACS Nano, 2017, 11, 5391-5404.

37. H. Yuan, E. Debroye, E. Bladt, G. Lu, M. Keshavarz, K. P. F. Janssen, M. B. J. Roeffaers, S. Bals, E. H. Sargent and J. Hofkens, Advanced Materials, 2018, 30, 1705494.

38 . It has recently been reported the dependence of the relative contribution of the PL decay components of perovskite nanoparticles, and hence the average PL lifetime, on the degree of the particle aggregation/assembly, see Ref. 39.

39. V. S. Chirvony, S. González-Carrero, I. Suárez, R. E. Galian, M. Sessolo, H. J. Bolink, J. P. Martínez-Pastor and J. Pérez-Prieto, The Journal of Physical Chemistry C, 2017, 121, 13381-13390. 40. L. C. Schmidt, A. Pertegás, S. González-Carrero, O. Malinkiewicz, S. Agouram, G. Mínguez Espallargas, H. J. Bolink, R. E. Galian and J. Pérez-Prieto, Journal of the American Chemical Society, 2014, 136, 850-853.

41. S. Yun, X. Zhou, J. Even and A. Hagfeldt, Angewandte Chemie International Edition, 2017, 56, 15806-15817.

42. S. Yun, Y. Qin, A. R. Uhl, N. Vlachopoulos, M. Yin, D. Li, X. Han and A. Hagfeldt, Energy \& Environmental Science, 2018, 11, 476526. 